\title{
OPEM
}

www.opem.org

Oriental Pharmacy and Experimental Medicine 2008 8(3), 252-259

DOI 10.3742/OPEM.2008.8.3.252

\section{Anti-pyretic and anti-inflammatory activity of chloroform extract of Croton roxburghii in standard animal models}

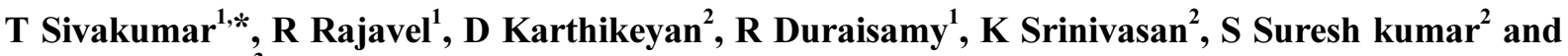 \\ Subhas S Karki ${ }^{3}$ \\ ${ }^{1}$ Nandha College of pharmacy, Natural Products Research Laboratory, Erode, Tamilnadu India, ${ }^{2}$ J.K.K.Nataraja \\ College of Pharmacy, Komarapalayam, Tamilnadu, India; ${ }^{3}$ KLES College of Pharmacy, Bangalore, India
}

Received for publication March 21, 2007; accepted December 13, 2007

\begin{abstract}
SUMMARY
The chloroform extract of Croton roxburghii (Family: Euphorbiaceae) was evaluated for its antipyretic effects in Brewer's yeast induced hyperthermia in rats. The anti-inflammatory effect of the Croton roxburghii was also evaluated by using carrageenan, dextran, histamine, serotonin induced rat paw oedema and cotton pellet induced granuloma (chronic) models in rats. The chloroform extract of Croton roxburghii (CECR) exhibited significant anti-pyretic and antiinflammatory effect at the dose 50, 100 and $200 \mathrm{mg} / \mathrm{kg}$. Maximum inhibition $(55.32 \%)$ was noted at the dose of $200 \mathrm{mg} / \mathrm{kg}$ after $3 \mathrm{~h}$ of drug treatment in carrageenan induced paw oedema, whereas the Indomethacin (standard drug) produced $61.33 \%$ of inhibition. The extract exhibited significant anti-inflammatory activity in dextran induced paw edema in a dose dependent manner. In the chronic model (cotton pellet induced granuloma) the CECR $(200 \mathrm{mg} / \mathrm{kg})$ and Indomethacin $(10 \mathrm{mg} / \mathrm{kg}$ ) showed decreased formation of granuloma tissue by $52.32 \%$ and $56.32 \%$ respectively. The extract also exhibited a significant antipyretic response in Brewer's yeast induced pyrexia in rats. Thus, the present study revealed that the CECR exhibited significant antipyretic and anti-inflammatory activity in the tested animal models.
\end{abstract}

Key words: Croton roxburghii; Carrageenan induced paw edema; Cotton pellet induced granuloma

\section{INTRODUCTION}

Medicinal plants have been used since ancient times as medicines for the treatment of diseases and still play a key role in world health. The chemical diversity of plants has made them one of the main sources for the isolation of bioactive organic compounds (Basso et al., 2005). However, studies have been continuing on inflammatory diseases and the side effects of the currently

\footnotetext{
*Correspondence: T Sivakumar, Nandha College of pharmacy, Natural Products Research Laboratory, Erode, Tamilnadu -638052, India. E-mail: sivaecp@hotmail.com
}

available anti-inflammatory drugs pose a major problem during their clinical use. Therefore, development of newer and more powerful antiinflammatory drugs with lesser side effects is necessary. The genus croton is a large one with 750 species of trees and shrubs distributed in tropical and subtropical regions of the both hemispheres. The croton family is rich in active alkaloids and several species of croton are well known as medicinal plants. Croton roxburghii (Family: Euphorbiaceae) is a medium sized tree. Different part of the plant was used by the local tribal (Andhra Predesh) people of India for the treatment 
of various disorders such as antifertility, snake venom, fever and wounds (Rama and Henry, 1997). Active constituents of the genus croton include proanthocyanidin, tannins, terpenes, alkaloids, flavones, and phenolic compounds (Cai et al., 1991; Hermandez and Delgado, 1992; Porras-Reyes et al., 1993). However, fewer reports are available with respect to the pharmacological properties of the plant. Hence, the present study was undertaken to evaluate the effect of the chloroform extract of Croton roxburghii (CECR) for its anti-pyretic activity by yeast-induced hyperpyrexia in rats. The extract also evaluate for the anti-inflammatory activity in acute and chronic models in rats. The effect of the extract was also compared with that of the standard drug, Indomethacin, a well-known antiinflammatory agent.

\section{MATERIALS AND METHODS}

\section{Plant material}

The plant Croton roxburghii (Family: Euphorbiaceae) was collected in the month of May 2006 from Nagarjunna Sagar Hills, Andhra Pradesh, India. The plant material was taxonomically identified by the Botanical survey of India, Coimbatore, Tamilnadu, India and the voucher specimen TSK-3 was retained in our laboratory for future reference.

\section{Chemicals and reagents}

The chemicals used in the present study were carrageenan (S. D. Fine Chemicals Limited, Bombay), histamine (Sigma, USA), 5-hydroxy tryptamine hydrochloride (serotonin) (Sigma, USA), dextran (Sigma, USA), paracetamol (Torrent, Bombay) and Indomethacin (IPCA, Bombay).

\section{Preparation of extract}

The dried powdered plant (bark) material was extracted with $80 \%$ methanol in a Soxhlet extraction apparatus. The solvent was removed under reduced pressure and semi solid mass was obtained. The semi solid mass was further partitioned with water and successively extracted with chloroform, ethyl acetate, and methanol. The solvent was completely removed under reduced pressure. The yield of chloroform, ethyl acetate, and methanol extract were 5.2, 3.4 and $6.2 \% \mathrm{w} / \mathrm{w}$ respectively. The chloroform extract, at the different doses of 50, 100 and $200 \mathrm{mg} / \mathrm{kg}$ was suspended in $0.25 \%$ carboxy methyl cellulose solution and Indomethacin $(10 \mathrm{mg} / \mathrm{kg})$ in saline was used for the present study.

\section{Phytochemical study profile}

The active part the chloroform extract subjected to chemical analysis to determine the classes of compounds present in it. The powdered bark of Croton roxburghii treated with ammonium hydroxide the resulting brownish red viscous mass was extracted with chloroform. The chloroform extract was concentrated under reduced pressured in vacuo and refrigerated. The resulting mass obtained from chloroform extract was chromotogramed by different solvent system. From the silica gel G thin layer chromatography using the solvent system n-butanol -acetic acid -water (4: 1: 1) was selected for the study and a single sport observed on TLC plate and spraying with dragendroff's reagent gave positive test for alkaloid. The $R_{f}$ value of the resulting compound was noted $\left(R_{\mathrm{f}}=0.65\right)$. The material was crystallized from hot methanol. The crystalline white compound, it is also shown a single spot on TLC, after spraying with Dragendroff's reagent gave positive test of alkaloid. The mass spectral studies on the compound indicates that the molecular ion peak ( $\mathrm{m} / \mathrm{z}$ 369: 58 (100). The isolated compound IR $\left(\mathrm{CHCl}_{3}\right)$ 3011, 2943, 2829, $2786,1600,1135,1090 \mathrm{~cm}^{-1}$ data suggested to a taspine already reported in the literature and the structure was identified and comparison with the published data (Vaisberg et al., 1989). The present study carried out the extract; it is due to the paucity of the sample of the compound. 


\begin{abstract}
Animals
Albino Wistar rats of the either sex (180 - $200 \mathrm{~g})$ were used for the present study. They were maintained under standard environmental conditions and were fed with standard pellet diet with water ad libitum.

\section{Toxicity study}

An acute toxicity study relating to the determination of $\mathrm{LD}_{50}$ was performed (Litchfield and Wilcoxon, 1949).
\end{abstract}

\section{Antipyretic activity}

\section{Study on normal body temperature}

Rats of either sex were divided into four groups, comprising six in each group for these experiments. The rectal temperature of each rat was measured initially and at every one hour interval for five hours after administration of both $0.25 \%$ carboxy methyl cellulose solution (control) and chloroform extract of the Croton roxburghii at the dose of 50, 100 , and $200 \mathrm{mg} / \mathrm{kg}$ respectively.

\section{Yeast induced hyperpyrexia in rats}

The antipyretic effect of CECR was evaluated in Wistar albino rats by the method of Loux et al., 1972). The rats were divided into five groups containing six in each and trained to remain quite in a restraint cage. A thermister probe was inserted 3 to $4 \mathrm{~cm}$ into the rectum and fastened to the tail adhesive tape. After measuring the basal rectal temperature, the animals were given subcutaneous injections of $10 \mathrm{ml} / \mathrm{kg}$ of $15 \% \mathrm{w} / \mathrm{v}$ yeast suspended in a $0.5 \% \mathrm{w} / \mathrm{v}$ methylcellulose solution. When the temperature was at peak ( $18 \mathrm{~h}$ after yeast injection) the rectal temperature recording were repeated. Those animals that showed a rise in rectal temperature of more than $1.2^{\circ} \mathrm{C}$ were used for the present study. The extract (CECR) was administrated interaperitoneally (i.p.) at 50, 100, and $200 \mathrm{mg} / \mathrm{kg}$ to three groups of rats respectively. Similar volumes ( $5 \mathrm{ml} / \mathrm{kg}$ ) of normal saline were injected to the control groups. The fifth group of rats received the antipyretic agent, paracetamol, at a dose of 150 $\mathrm{mg} / \mathrm{kg}$ i.p. Rectal temperatures were recorded immediately before CECR, Paracetamol or vehicle administration and again at 20,21, 22, and $23 \mathrm{~h}$ after yeast injection.

\section{Anti-inflammatory activity Carrageenan - induced rat paw edema}

The rats were divided into 5 groups $(n=6)$. Acute inflammation was produced by the subplantar administration of $0.1 \mathrm{ml}$ of $1 \%$ carrageenan in normal saline in the right paw of the rats. Different groups were treated with CECR (50, 100 and 200 $\mathrm{mg} / \mathrm{kg})$, Indomethacin $(10 \mathrm{mg} / \mathrm{kg})$ and control vehicle were administered orally. The paw volume was measured at $0 \mathrm{~h}$ and $3 \mathrm{~h}$ after carrageenan injection using plethysmometer (Winter et al., 1957). The animals were pretreated with the extract $1 \mathrm{~h}$ before the administration of carrageenan. The extract and the standard drug used for this study were prepared in the same manner as mentioned earlier. The ratio of the anti-inflammatory effect of CECR was calculated by the following equation: anti-inflammatory activity $(\%)=\left(\mathrm{P}_{1}-\mathrm{P}_{2} / \mathrm{P}_{1}\right) \times 100$, where $\mathrm{P}_{1}$ represents the paw volume of control rats, and $\mathrm{P}_{2}$ represents the paw volume of the treated groups.

\section{Dextran induced paw edema}

The animals were treated as in case of carrageenan induced paw edema models, except that in place of carrageenan, dextran $(0.1 \mathrm{ml}, 1 \% \mathrm{w} / \mathrm{v}$ in normal saline) was used (Parmar and Ghosh, 1978).

\section{Mediator induced inflammation}

The anti-inflammatory activity of the extract was measured with phlogistic agents (viz. histamine, 5-hydroxy tryptamine hydrochloride) which are act as mediator of inflammation. The paw edema was induced in rats by sub plantar injection of freshly prepared histamine $(1 \mathrm{mg} / \mathrm{kg})$ and serotonin $(1 \mathrm{mg} / \mathrm{kg})$ solutions respectively. The paw edema was measured as mentioned earlier (Parmer and Ghosh, 1978). 


\section{Cotton pellets-induced granuloma}

The inflammation was produced by cotton pellets induced granuloma (Winter et al., 1962). The rats were divided into five groups $(n=6)$. After shaving the fur, the rats were anaesthetized and $10 \mathrm{mg}$ of sterile cotton pellets were inserted, one in each axilla. The CECR (50, 100 and $200 \mathrm{mg} / \mathrm{kg}$, p.o.), Indomethacin (10 mg/kg, p.o.), and control vehicle were administered orally for 7 consecutive days from the day of cotton pellet implantation. The animals were anaesthetized on the eighth day and cotton pellets were removed surgically and made free from extraneous tissues. The pellets were incubated at $37^{\circ} \mathrm{C}$ for $24 \mathrm{~h}$ and dried at $60{ }^{\circ} \mathrm{C}$ to constant weight. Increment in the dry weight of the pellets was taken as a measure of granuloma formation.

\section{Statistical analysis}

The results are expressed as mean \pm S.E.M. The statistical analysis was performed by ANOVA test.

\section{RESULTS}

The chloroform extract of Croton roxburghii was subjected to chromotogramed by using different solvent system. It was determined by identification reactions based on the chemical group to be determined or thin layer chromatography. From the thin layer chromatography the chloroform extract of Croton the spot from the chromatogram med to be alkaloid by using spraying reagent dragendroff's gave positive test for alkaloid. Due to diminutive quantity of the isolated compound, hence, we undertaken the crude part of the chloroform extract Croton roxburghii was carried out the present study.

The CECR was evaluated for antipyretic and anti-inflammatory activity in standard experimental animal models and the results are summarized in Table 1, 2,3,4, and 5. The chloroform extract exhibited significant anti-pyretic anti-inflammatory activity at the tested doses of 50, 100 and $200 \mathrm{mg} / \mathrm{kg}$ in a dose dependant manner. Effect of the CECR on the

Table 1. Effect of chloroform extract of Croton roxburghii on normal body temperature in rats

\begin{tabular}{cccccccc}
\hline \multicolumn{7}{c}{ Rectal temperature in ${ }^{\circ} \mathrm{C}$ before and after the medication } \\
\hline Treatment & $\begin{array}{c}\text { Dose } \\
\text { mg/kg (i.p. })\end{array}$ & $0 \mathrm{~h}$ & $1 \mathrm{~h}$ & $2 \mathrm{~h}$ & $3 \mathrm{~h}$ & $4 \mathrm{~h}$ & $5 \mathrm{~h}$ \\
\hline $\begin{array}{c}\text { Normal Saline } \\
(0.9 \% \mathrm{NaCl} \mathrm{w} / \mathrm{v})\end{array}$ & $5 \mathrm{ml} / \mathrm{kg}$ & $37.2 \pm 0.1$ & $37.2 \pm 0.2$ & $37.3 \pm 0.2$ & $37.2 \pm 0.3$ & $37.4 \pm 0.3$ & $37.2 \pm 0.3$ \\
$\mathrm{CECR}$ & 50 & $37.2 \pm 0.3$ & $37.2 \pm 0.2$ & $36.6 \pm 0.2$ & $36.8 \pm 0.4$ & $37.2 \pm 0.5$ & $37.4 \pm 0.17$ \\
CECR & 100 & $37.1 \pm 0.2$ & $37.2 \pm 0.3$ & $36.4 \pm 0.3$ & $36.3 \pm 0.2$ & $36.2 \pm 0.6$ & $36.1 \pm 0.2$ \\
CECR & 200 & $37.2 \pm 0.2$ & $36.5 \pm 0.5$ & $35.8 \pm 0.4$ & $36.2 \pm 0.4$ & $35.9 \pm 0.2$ & $35.7 \pm 0.2$ \\
\hline
\end{tabular}

Each value represents mean \pm S.E.M. of six rats. Statistical significance was compared with normal.

Table 2. Effect of chloroform extract of Croton roxburghii on yeast-induced pyrexia in rats

\begin{tabular}{lcccccc}
\hline \multicolumn{7}{c}{ Rectal temperature in ${ }^{\circ} \mathrm{C}$ before and after the medication } \\
\hline Treatment & $0 \mathrm{~h}$ & $19 \mathrm{~h}$ & $20 \mathrm{~h}$ & $21 \mathrm{~h}$ & $22 \mathrm{~h}$ & $23 \mathrm{~h}$ \\
\hline Vehicle $5 \mathrm{ml} / \mathrm{kg}$ & $37.2 \pm 0.2$ & $39.3 \pm 0.2$ & $39.4 \pm 0.2$ & $39.2 \pm 0.2$ & $39.3 \pm 0.3$ & $39.3 \pm 0.2$ \\
CECR $50(\mathrm{mg} / \mathrm{kg})$ & $37.1 \pm 0.2$ & $39.3 \pm 0.1$ & $38.5 \pm 0.3$ & $38.1 \pm 0.4$ & $37.7 \pm 0.5$ & $37.5 \pm 0.1$ \\
CECR $100(\mathrm{mg} / \mathrm{kg})$ & $37.3 \pm 0.2$ & $39.4 \pm 0.2$ & $37.9 \pm 0.2$ & $37.2 \pm 0.2$ & $36.5 \pm 0.6$ & $36.2 \pm 0.2^{\mathrm{a}}$ \\
CECR 200 $(\mathrm{mg} / \mathrm{kg})$ & $37.2 \pm 0.2$ & $39.2 \pm 0.3$ & $37.3 \pm 0.3$ & $36.4 \pm 0.4^{\mathrm{a}}$ & $36.2 \pm 0.2^{\mathrm{a}}$ & $36.7 \pm 0.3^{\mathrm{a}}$ \\
Paracetamol 150 $(\mathrm{mg} / \mathrm{kg})$ & $37.1 \pm 0.3$ & $39.6 \pm 0.3$ & $37.2 \pm 0.3$ & $36.4 \pm 0.3^{\mathrm{a}}$ & $36.1 \pm 0.3^{\mathrm{a}}$ & $37.3 \pm 0.3$ \\
\hline
\end{tabular}

Each value represents mean \pm S.E.M. of six rats. ${ }^{\mathrm{a}} P<0.01$ Statistically different from the rectal temperature with $19 \mathrm{~h}$ yeast injection. 
Table 3. Effect of the Croton roxburghii extract on carrageenan and dextran induced pedal oedema

\begin{tabular}{cccc}
\hline Treatment & Dose $(\mathrm{mg} / \mathrm{kg})$ & Paw volume $(\mathrm{ml})$ & Inhibition $(\%)$ \\
\hline Carrageenan control & 0 & $0.732 \pm 0.063$ & - \\
Indomethacin & 10 & $0.283 \pm 0.024$ & 61.33 \\
CECR & 50 & $0.446 \pm 0.035$ & 39.07 \\
CECR & 100 & $0.403 \pm 0.028$ & 44.90 \\
CECR & 200 & $0.327 \pm 0.017$ & 55.32 \\
\hline Dextran control & 0 & $0.629 \pm 0.047$ & - \\
Indomethacin & 10 & $0.247 \pm 0.015$ & 60.73 \\
CECR & 50 & $0.426 \pm 0.041$ & 32.27 \\
CECR & 100 & $0.360 \pm 0.030$ & 42.76 \\
CECR & 200 & $0.295 \pm 0.027$ & 53.10
\end{tabular}

Values are mean \pm S.E.M. $(n=6)$. Experimental groups were compared with control $P<0.001$.

Table 4. Effect of Croton roxburghii extract on mediators like histamine and 5-HT induced pedal oedema in rats

\begin{tabular}{cccc}
\hline Treatment & Dose $(\mathrm{mg} / \mathrm{kg})$ & Paw volume $(\mathrm{ml})$ & Inhibition $(\%)$ \\
\hline Histamine control & 0 & $0.544 \pm 0.045$ & - \\
Indomethacin & 10 & $0.207 \pm 0.022$ & 61.94 \\
CECR & 50 & $0.328 \pm 0.030$ & 36.70 \\
CECR & 100 & $0.298 \pm 0.024$ & 45.22 \\
CECR & 200 & $0.251 \pm 0.021$ & 53.86 \\
\hline Serotonin control & 0 & $0.623 \pm 0.045$ & - \\
Indomethacin & 10 & $0.256 \pm 0.017$ & 59.73 \\
CECR & 50 & $0.407 \pm 0.035$ & 34.67 \\
CECR & 100 & $0.361 \pm 0.033$ & 43.01 \\
CECR & 200 & $0.295 \pm 0.020$ & 52.64 \\
\hline
\end{tabular}

Values are mean \pm S.E.M. $(\mathrm{n}=6)$. Experimental groups were compared with control $P<0.001$.

Table 5. Effect of the Croton roxburghii extract on cotton-pellets induced granuloma in rats

\begin{tabular}{cccc}
\hline Treatment & Dose $(\mathrm{mg} / \mathrm{kg})$ & Weight of cotton pellet $(\mathrm{mg})$ & Inhibition $(\%)$ \\
\hline Control & 0 & $47.4 \pm 3.2$ & - \\
Indomethacin & 10 & $20.7 \pm 1.5$ & 56.32 \\
CECR & 50 & $33.9 \pm 1.7$ & 28.48 \\
CECR & 100 & $27.9 \pm 1.8$ & 41.13 \\
CECR & 200 & $22.6 \pm 2.1$ & 52.32 \\
\hline
\end{tabular}

Values are mean \pm S.E.M. $(n=6)$. Experimental groups were compared with control $P<0.001$.

normal body temperature in rats is presented in Table 1. This effect was maximal at the doses of 100 and $200 \mathrm{mg} / \mathrm{kg}$ in a dose dependent manner and it caused significant lowering of body temperature up to $5 \mathrm{~h}$ after its administration.

As displayed in Table 2, the extract of Croton roxburghii at the dose 100 and $200 \mathrm{mg} / \mathrm{kg}$ caused a significant lowering in rectal temperature of hyperthermic rats. The decrease in rectal temperature still existed when assessment was made $3 \mathrm{~h}$ after test drug administration and efficacy was comparable to that of standard drug paracetamol at the dose of $150 \mathrm{mg} / \mathrm{kg}$.

As shown in Table 3 - 5, the chloroform extract showed maximum inhibition of $55.32 \%$ at the dose of $200 \mathrm{mg} / \mathrm{kg}$ after $3 \mathrm{~h}$ of drug treatment in 
carrageenan induced paw edema, whereas the standard drug showed $61.33 \%$ of inhibition. In dextran induced paw edema the chloroform extract showed significant inhibition $(32.27 \%, 42.76 \%$, and $53.1 \%$ ) in a dose dependent manner as compared with control. As shown in Table 4, in case of histamine and serotonin induced paw edema, the chloroform extract showed $53.86 \%$ and $52.64 \%$ of inhibition at the dose of $200 \mathrm{mg} / \mathrm{kg}$ whereas indomethacin showed $61.94 \%$ and $59.73 \%$ of inhibition, respectively. As shown in Table 5, in the chronic model (cotton pellet induced granuloma), the CECR $(200 \mathrm{mg} / \mathrm{kg})$ and standard drug showed decreased formation of granuloma tissue at $52.32 \%$ and $56.32 \%(P<0.001)$, respectively.

\section{DISCUSSION}

The potential of the CECR for its antipyretic and anti-inflammatory effect was investigated. Since antipyretic activity is commonly mentioned as a characteristic of drugs or compounds which have an inhibitory effect on prostaglandin-biosynthesis (Vane, 1987), the yeast-induced hyperthermia in rat model was employed to investigate the antipyretic activity of the chloroform extract of Croton roxburghii. Regulation of body temperature requires a delicate balance between production and loss of heat and the hypothalamus regulate the set point at which body temperature is maintained. In fever this set point elevated and the drug like paracetamol do not influence body temperature when it is elevated by the factors such as exercise or increase in ambient temperature (Gilman, 1990). The present investigation indicated that the chloroform extract of Croton roxburghii shown significant anti-pyretic effect. The result seems to support the view that the chloroform extract has some influence on prostaglandin-biosynthesis because prostaglandin is believed to be a regulator of body temperature (Milton, 1982).

The CECR was also evaluated for its antiinflammatory activity in acute and chronic models.
Significant anti-inflammatory activity was observed for CECR in both carrageenan and dextran induced edema models. The chloroform extract showed maximum inhibition of $55.32 \%$ at the dose of $200 \mathrm{mg} / \mathrm{kg}$ after $3 \mathrm{~h}$ of drug treatment in carrageenan induced paw edema. The carrageenaninduced edema is the preliminary screening models for searching for potential anti-inflammatory compounds. Edema formation is believed to be biphasic, of which the first phase is mediated by the release of histamine and 5-HT followed by kinin release and then prostaglandin in the later phase (Castro et al., 1968; Alcarz and Jimenez, 1988). The CECR also exhibited significant antiinflammatory property in dextran induced paw oedema model (Parmer and Ghosh, 1978). Dextran induced paw edema is known to be mediated both by histamine and serotonin. Dextran induces fluid accumulation, which contains little protein and few neutrophils, whereas carrageenan induces protein rich exudation containing large number of neutrophils. The extract effectively suppressed the inflammation produced by both carrageenan and dextran.

Mast cell mediators include arachidonic acid products, biogenic amines, chemo attractants, cytokines, and growth factors, neuropeptides, proteoglycans, and proteolytic enzymes. (Schwartz, 1987; Serafin and Austen, 1987; Kobayashi et al., 2000). Mast cells are increasingly recognized as key cells in the development of a number of inflammatory diseases (Theoharides, 1996; Marone et al., 2002) including the skin, (Maurer et al., 2003) joints, (Wasserman, 1984; Tetlow and Woolley, 1995) and urinary bladder, (Theoharides, 2002) that worsen by stress. The extract also effectively suppressed the inflammation produced by mediator's viz. histamine and serotonin (5-HT). The CECR exhibited a significant inhibition against histamine and 5-HT induced hind paw edema, which indicates that the extracts exhibits its anti-inflammatory action by means of either inhibiting the synthesis, release or action of inflammatory mediators viz. 
histamine, serotonin and prostagandins might be involved in inflammation. So, it may be suggested that its anti-inflammatory activity is possible backed by its antihistaminic activity.

The cotton pellet granuloma widely used to evaluate the transudative and proliferative components of the chronic inflammation. The moist weight of the pellets correlates with transuda, the dry weight of the pellet of the correlates with the amount of granulumatous tissues (Dunne, 1990). Chronic inflammation occurs by means of the development of proliferative cells. These cells can be either spread or in granuloma form. The CECR showed significant anti-inflammatory activity in cottonpellet induced granuloma and thus found to be effective in chronic inflammatory conditions, which reflected its efficacy in inhibiting the increase in the number of fibroblasts and synthesis of collagen and mucopolysaccharides during granuloma tissue formation (Arrigoni-Maratellie, 1988). From these observations it can be indeed inferred that the endogenous chemical substances liberated during pain, inflammation and fever like histamine, serotonin and arachidonic cascade metabolites are inhibited to produce various activities highlighted in this study.

The present screening permits to support, in part, the attributed properties of the evaluated species, often reported to treat ailments in which inflammatory processes could be involved. Taspine alkaloid was also isolated from the same species like Croton lechleri (Vaisberg et al., 1989). The biological activity of taspine was also reported with respect of anti-inflammatory activity (Perdue et al., 1979), a reverse transcriptase inhibitory activity and wound healing activities (Vaisberg et al., 1989). From the studies the presence of alkaloid taspine in Croton roxburghii was may be responsible for the antipyretic and anti-inflammatory activity.

\section{ACKNOWLEDGEMENTS}

The authors are thankful to The Chairman shri. V.
Shanmugan, and secretary S. Nandha Kumar Pradeep M.B.A., Nandha Educational trust, Erode, Tamilnadu, India, for the help rendered in all academic and monitory aspects.

\section{REFERENCES}

Alcaraz MJ, Jimenez MI. (1988) Flavonoids as antiinflammatory agents. Fitoterapia 59, 25-38.

Arrigoni-Maratellie E. (1988) Inflammation and Antiinflammatory: Spectrum Publication Inc, New York, pp. 119-120.

Basso LA, da Silva LH, Fett-Neto AG, de Azevedo Jr WF, Moreira Ide S, Palma MS, Calixto JB, Astolfi Filho S, dos Santos RR, Soares MB, Santos DS. (2005) The use of biodiversity as source of new chemical entities against defined molecular targets for treatment of malaria, tuberculosis, and T-cell mediated diseases. a Review. Mem. Inst. Oswaldo Cruz 100, 475-506.

Cai Y, Evans FJ, Roberts MF, Phillipson JD, Zenk MH, Gleba YY. (1991) Polyphenoli compounds from Croton lechleri. Phytochemistry 30, 2033-2040.

Castro J, Sasame H, Sussaman H, Buttette P. (1968) Diverse effect of SKF 52 and antioxidants of $\mathrm{CCl}_{4}$ induced changes in liver microsomal P-450 content and ethyl-morphine metabolism. Life Sci. 7, 83-86.

Dunne MW. (1990) Pathophysiology: "Concepts of altered Health States with Contributors", ed. by Porth C.M., Lippincott, Philadelphia, pp. 165-176.

Gilman AG, Rav TW, Nies AS, Taylor P. (1990) The Pharmacological Basis of Therapeutics, Pergamon Press, NY, p. 935.

Hermandez J, Delgado G. (1992) Determination of free and total cholesterol by direct chloroform extraction. J. Biol. Chem. 180, 315-328.

Kobayashi H, Ishizuka T, Okayama Y. (2000) Human mast cells and basophils as sources of cytokines. Clin. Exp. Allergy. 30, 1205-1212.

Litchfield JT, Jr Wilcoxon F. (1949) A simplified of evaluating dose-effect experiments. J. Pharmacol. Exp. Ther. 96, 99-135.

Loux JJ, Depalma PD, Yankell SC (1972) Antipyretic testing of aspirin in rats. Toxicol. Appl. Pharmacol. 22, 672-675.

Maity TK, Mandal SC, Mukherjee PK. (1998) Studies on anti-inflammatory effect of Cassia tora leaf extract 
(Fam.Legumirosae). Phytother. Res. 12, 221-223.

Marone G, Galli SJ, Kitamura Y. (2002) Probing the roles of mast cells and basophils in natural and acquired immunity, physiology and disease. Trends Immunol. 23, 425-427.

Maurer M, Theoharides T, Granstein RD, Bischoff SC, Bienenstock J, Henz B, Kovanen P, Piliponsky AM, Kambe N, Vliagoftis H, Levi-Schaffer F, Metz M, Miyachi Y, Befus D, Forsythe P, Kitamura Y, Galli S. (2003) What is the physiological function of mast cells? Exp. Dermatol. 12, 886-910.

Milton AS. (1982) Prostaglandins and fever. Trends Pharmacol. Sci. 40, 490-492.

Parmar NS, Ghosh MN. (1978) Anti-inflammatory activity of gossypin bioflavonoid isolated from Hibscus Viofolius Linn. Indian J. Pharmacol. 10, 227293.

Persinos Perdue G, Blomster RN, Blake DA, Farnsworth. (1979) South American Plants II: Taspine Isolation and Anti-inflammatory activity. J. Pharm. Sci. 68, 124.

Porras-Reyes BH, Lewis WH, Roman J, Simchowitz L, Mustoe TA. (1993) Enhancement of wound healing by the alkaloid taspine defining mechanism of action. Pro. Soc. Exp. Biol. Med. 203, 18-25.

Rama Rao N, Henry AN. (1997) Ethanobotany of Easternghats of Andhra Pradesh, Botanical Survey of India, Kolkata, pp.68, 150.

Schwartz LB. (1987) Mediators of human mast cells and human mast cell subsets. Ann. Allergy 58, 226-235.

Smith PK, Hambourger WE. (1935) The ratio of toxicity of acetanilide to its antipyretic in Rats. J. Pharmacol. Exp. Ther. 54, 346-348.
Serafin WE, Austen KF. (1987) Mediators of immediate hypersensitivity reactions. N. Engl. J. Med. 317, 30-34.

Tetlow LC, Woolley DE. (1995) Distribution, activation and tryptase/ chymase phenotype of mast cells in the rheumatoid lesion. Ann. Rheum. Dis. 54, 549-555.

Theoharides TC. (1996) The mast cell: a neuroimmunoendocrine master player. Int. J. Tissue React. 18, 1-21.

Theoharides TC. (2002) Mast cell and stress: a psychoneuroimmunological perspective. J. Clin. Psychopharmacol. 22, 103-108.

Theoharides TC, Cochrane DE. (2004) Critical role of mast cells in inflammatory diseases and he effect of acute stress. J. Neuroimmunol. 146, 1-12.

Vaisberg AJ, Milla M, Planas MC, Cordova JL, de Agusti ER, Ferreyra R, Mustiga MC, Carlin L, Hammond GB. (1989) Taspine is the cicatrizant principle in Sangre de Grado extracted from Croton lechleri. Planta Med. 55, 140-143.

Wasserman SI. (1984) The mast cell and synovial inflammation. Arthritis Rheum. 27, 841-844.

Winter CA, Poster CC. (1957) Effect of alteration in side chain upon anti-inflammatory and liver glycogen activities in hydrocortisone esters. J. Am. Pharm. Assoc. 46, 515-519.

Winter CA, Risely EA, Nuss GW. (1962) Carregeenin induced oedema in bind paw of he rat as assay for anti-inflammatory drugs. Proc. Soc. Exp. Biol. Med. 111, 544-547.

Wintrobe MM, Lee GR, Boggs DR, Bithel TC, Athens JW, Foerester J. (1961) In: Clinical Hematology, $5^{\text {th }}$ ed, Lea and Febiger, Philadelphia, pp. 326. 